\title{
Research and application of electro hydraulic proportional synchronous control system based on PID algorithm
}

\author{
Gang Wang \\ Sichuan Information Technology College, Guangyuan 628017, China \\ 18493621@qq.com
}

Keywords: AMESim; electro hydraulic proportional valve; synchronization system; PID; genetic algorithm

\begin{abstract}
The electro-hydraulic proportional speed synchronization system is studied, and the system physical model is built by the advanced modeling and simulation software AMESim, and the dynamic characteristics are simulated and analyzed. In order to improve the response time, steady-state accuracy, stability and synchronization of the system, the PID controller parameters are optimized by using genetic algorithm to control the speed accuracy of hydraulic motor. The simulation results show that the optimized parameters can improve the system performance and achieve good results, thus providing a technical support for the optimization design of mechatronic systems.
\end{abstract}

\section{Introduction}

With the development of industrial machinery, engineering machinery and testing equipment of synchronous drive technology of the synchronization accuracy requirements more and higher, in many occasions in hydraulic motor as synchronous driving device has simple structure, convenient combination and is suitable for high power characteristics, its application is more and more widely. Good synchronous control method is an important factor to realize its function and improve its performance. In this study, the system model is built in AMESim software, using closed loop synchronization control, the system feedback correction and application the batch processing tools and optimization function of genetic algorithm on valve controlled motor speed synchronization system PID parameters were optimized based on, in increase with step motor tracking performance based on the system of fast, accurate and stable.

\section{Composition and principle of electro hydraulic proportional synchronous speed system}

The principle of electro hydraulic proportional synchronous speed system is shown in Figure 1. System is mainly composed of a filter 1, a quantitative pump 2 and a motor 3, overflow valve 4, storage can device and the electric hydraulic proportional directional valve 6 and 7, double acting motor 8 and 9, speed sensor 10 and 11, load composition of 12 and 13. In the electro hydraulic proportional synchronous speed system, as shown in Figure 1, on the right side of the valve controlled motor system as the main system, speed sensor and load of the crankshaft is connected for detecting the rotational speed of the shaft load, motor speed information to dynamically detect and through the data acquisition card is passed to the computer, and command signal for comparison, the formation of the deviation signal proportional controller will be the amplification and conversion for current signal to pass to the electro-hydraulic proportional valve, control valve opening to control flow through the electro-hydraulic proportional valve of the hydraulic oil, and ultimately the formation of closed loop control system of main motor speed. The left side of the valve controlled motor system for the system to synchronize, the synchronous motor system in active system speed sensor signal do follow the movement, through the speed sensor signal feedback form the closed-loop speed control system. The PID controller is used to control the performance of the main system and the synchronization system. 


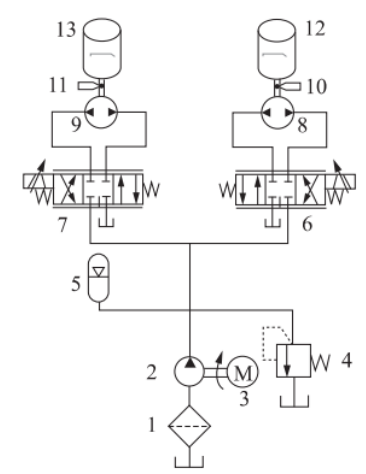

Fig. 1 Schematic diagram of electro hydraulic proportional speed synchronization system

According to the classical control theory, the proportion of $\mathrm{P}$ is the most basic control function, the transient response is fast, and the variation of the General Assembly decreases the steady-state error, but it will decrease the stability of the system. Integral link in the output error is not too large, the rapid adjustment of output. The differential link D can predict the difference between the output and the reference, and can adjust the output very fine.

\section{Simulation and analysis of electro hydraulic proportional synchronous speed system}

\subsection{System modeling}

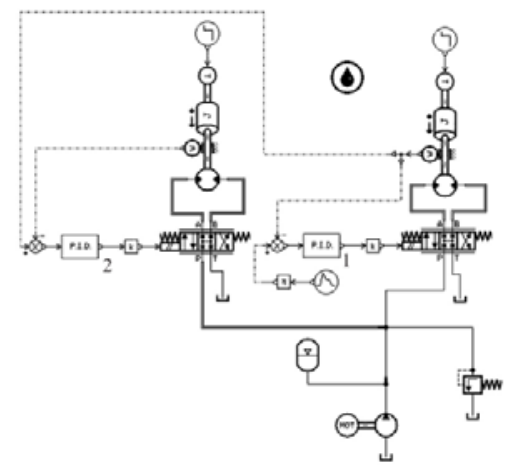

Fig. 2 Simulation model of electro hydraulic proportional speed synchronous system

In a number of simulation software and AMESim modeling is simple and convenient, because it is based on power bond graph graphical modeling was developed and will be able to free the user from complex mathematical modeling process, thus more attention to the process of system design and optimization. The electro-hydraulic proportional synchronous speed system was established by application of AMESim software, as shown in figure 2.

\subsection{System parameter setting}

After the system model is established, the main parameters of each model are shown in Table 1. The system of motors, pumps, valves and motors, etc. parameter setting is mainly according to the actual system parameters selected, using step signal simulation of disturbance and the desired motor speed with piecewise linear signal source to simulate. The PID1 controller is used to control the performance of the motor in the main system, and the synchronization system is controlled by the PID2 of the motor, and the initial parameters of the PID are determined according to the experience. Other parameters, such as liquid viscosity coefficient, temperature and other important parameters is considered in the normal state, then select model library of AMESim software provides the preferred parameters can meet the requirements. 
Table 1 Parameter setting table

\begin{tabular}{|c|c|}
\hline Parameter & Parameter values \\
\hline Rated speed of motor/r $\cdot$ min-1 & 1500 \\
\hline Pump rated displacement/mL $\cdot \mathrm{r}-1$ & 32 \\
\hline Relief valve opening pressure/MPa & 7 \\
\hline Rated current of proportional valve/mA & 40 \\
\hline Proportional valve natural frequency/Hz & 70 \\
\hline Proportional valve damping ratio & 0.8 \\
\hline Proportion of PID1 and PID2 kp & 100 \\
\hline Integration of PID1 and PID2 ki & 1 \\
\hline PID1 and PID2 differential link kd & 0.1 \\
\hline Speed sensor gain & 0.01 \\
\hline Motor displacement/mL $\cdot \mathrm{r}-1$ & 25 \\
\hline Piecewise linear signal & 500 \\
\hline Load moment of inertia/kg $\cdot \mathrm{m} 2$ & 0.5 \\
\hline Step signal instruction & 1 \\
\hline
\end{tabular}

The performance index of the system is: the system expected main and secondary motor speed is $500 \mathrm{r} / \mathrm{min}$, and the command signal error is less than $5 \mathrm{r} / \mathrm{min}$; The tracking error of the driven motor speed and the active motor speed is less than $2 \mathrm{r} / \mathrm{min}$; Dynamic tracking maximum error is less than $10 \mathrm{r} / \mathrm{min}$; Main and secondary motor adjust the time is less than $2 \mathrm{~s}$.

\subsection{System simulation and analysis}

To state clearly seen that the system is stable in system simulation, the simulation time for $20 \mathrm{~s}$; considering that the system may oscillate, communication interval set 0.01 seconds. Only in this way can more intuitive from the curve that each motor speed and stability. The speed of the motor and the deviation results are shown in Figure 3 and Figure 4.

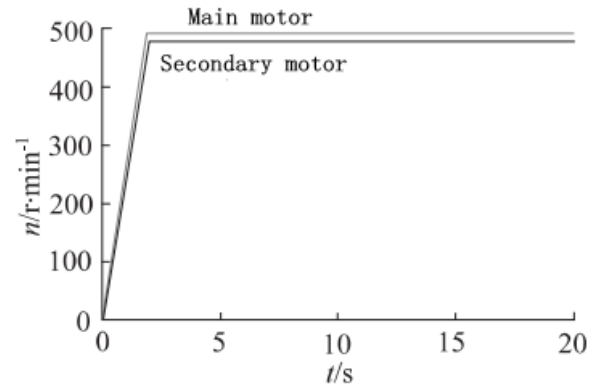

Fig. 3 Main and secondary motor speed curve

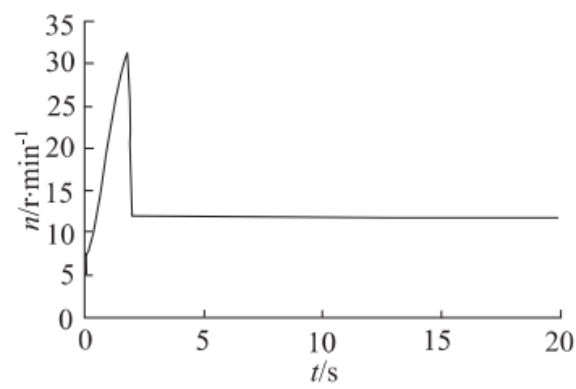

Fig. 4 Main and secondary motor speed deviation curve

In Figure 3, we can see that the speed of main motor and secondary motor reached $488.2 \mathrm{r} / \mathrm{min}$ and $476.1 \mathrm{r} / \mathrm{min}$ in the $2 \mathrm{~s}$. Due to existence of the system low speed and storage devices, motor speed is stable. But there was apparent steady-state error, and accuracy cannot meet the requirements. As can be seen in Figure 4, the stable rotational speed deviation is $12.1 \mathrm{r} / \mathrm{min}$, and the expected value of the steady-state tracking error was less than $2 \mathrm{r} / \mathrm{min}$, and not satisfied.

In this case, it is necessary to optimize the parameters of PID controller, so that the system can achieve very good accuracy on the basis of fast response and stability. Therefore, under the condition of the physical system, the control strategy of the main and secondary motor is set out from the system. Firstly, the parameters of PID1 are optimized, so that the speed performance of the active motor can reach the expected target. On the basis of the first step optimization, the parameters of PID2 are optimized so that the speed of the driven motor and the performance of the following performance can be achieved. 


\section{Optimization and analysis of electro hydraulic proportional synchronous speed system}

On the basis of the control strategy, the two PID controllers are optimized to improve the system performance, which can achieve the required standard. AMESim in the system to optimize the design, it is important to use its two functions: batch, genetic algorithm. Batch processing is will be a group of data to carry on the initial value and the step of setting, you can quickly determine the precise scope of parameter values, genetic algorithm with search in the global scope within a given, and find out the optimal solutions of the characteristics. Therefore, using the genetic algorithm to search the optimal solution can be used to reduce the workload and improve the efficiency of the optimization parameters.

\subsection{Optimization design based on AMESim}

AMESim software provides a tool for designing and exploring. In this module, a parameter optimization tool based on genetic algorithm is included. This research applies this tool to optimize the PID parameters.

\subsection{Optimization and analysis of the performance parameters of the main motor}

(1) Determine the optimization objectives

To improve the speed response of the motor speed, and shorten the adjustment time, that is, the deviation between the input terminal and output corresponding to the allowable range of the time in the process of experience. The allowable rotational speed deviation of the driving motor is $5 \mathrm{r} / \mathrm{min}$, and the adjustment time is the required time for the main motor to increase from $0 \mathrm{r} / \mathrm{min}$ to $495 \mathrm{r} / \mathrm{min}$. At the same time, the control precision is improved, and the steady state speed of the motor and the difference of the command signal are stable.

(2) The adjustment range of PID1 three parameters is determined

The three parameters of PID1 were batch processed. Finally, the optimization range was as follows: proportion parameter Kp1: $400 \sim$ 100, integral parameter Ki1: $0 \sim 10$, differential parameter Kd1: $0 \sim 10$.

(3) Specify the input and output parameters and constraints

The Kp1, Ki1 and Kd1 were set as the input parameters in the output setting dialog. The active motor speed was the output parameter, and the adjustment time and speed deviation error were the compound output parameters: response Time (shaftspeed, 495), globMax (abs (restrict (shaftspeed, 1, 20)-500)).

(4) Using the genetic algorithm to optimize the AMESim design exploration tool

Set the population size is 30 , the reproduction rate is 0.8 , the maximum algebra of the genetic algorithm is 20 , the variation probability is 0.1 , and the variation amplitude is 0.2 . PID1 optimization results: $\mathrm{Kp} 1=254.26$, Ki1 $=1.96659$, $\mathrm{Kd} 1=1.30529$.

As shown in Figure 5, optimized the main motor speed is steady $498.9 \mathrm{r} / \mathrm{min}$, the steady state error is $1.1 \mathrm{r} / \mathrm{min}$, and far less than $5 \mathrm{r} / \mathrm{min}$. It is meet the accuracy requirements. Adjusting time is 1.92s to achieve the performance index, and meet the requirements of the fast. While the motor speed is stable, and meet the performance index.

\subsection{Optimization and analysis of performance parameters of motor}

The parameters of the PID1 controller are maintained after the first step to optimize the results. By using the method of the last step, the optimal range of PID2 was determined by batch process as follows: Kp2: $800 \sim$ 500, Ki2: $0 \sim$ 10, Kd2: $0 \sim$ 10. The Kp2, Ki2 and Kd2 were set as input parameters in the output setting dialog, the slave motor speed shaftspeed2 was the output parameter, and the slave motor speed deviation error2 was the compound output parameter: globMax (abs (shaftspeed-shaftspeed2)). Using the genetic algorithm to optimize the design and exploration tool, the results of PID2 optimization: Kp2=699.967, Ki2 = 2.21924, Kd2 = 9.9958.

As shown in Figure 6, optimized the secondary motor speed was steady $497.2 \mathrm{r} / \mathrm{min}$, the steady state error was $2.8 \mathrm{r} / \mathrm{min}$, and less than $5 \mathrm{r} / \mathrm{min}$. It is meet the accuracy requirements. Adjusting time was 1.90 s to achieve the performance index, and meet the requirements of the fast. While the motor speed was stable, and meet the performance index. As shown in Figure 7, the speed of the main and secondary motor was stable at between 496 to $500 \mathrm{r} / \mathrm{min}$, the system performance was stable. At the 
same time, the adjustment time was within 2s, and the rapidity, accuracy and stability were satisfied. As shown in Figure 8, the maximum tracking error of the main and secondary motor is $5.6 \mathrm{r} / \mathrm{min}$, which is stable at the expected value of less than $2 \mathrm{r} / \mathrm{min}$. It can be seen that the control strategy is based on the actual physical system. By optimizing the parameters of the PID controller, the aim of improving the performance of the system is finally achieved.

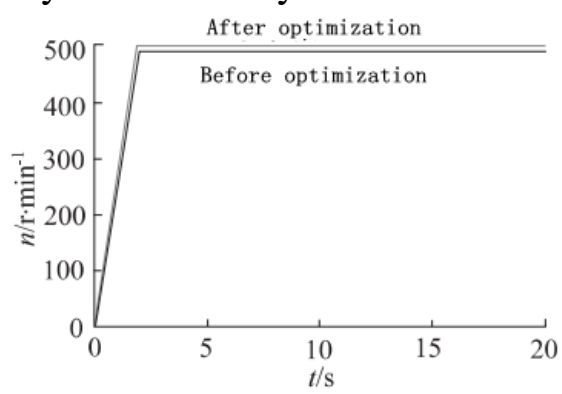

Fig. 5 The curve before optimization and the optimization of the main motor

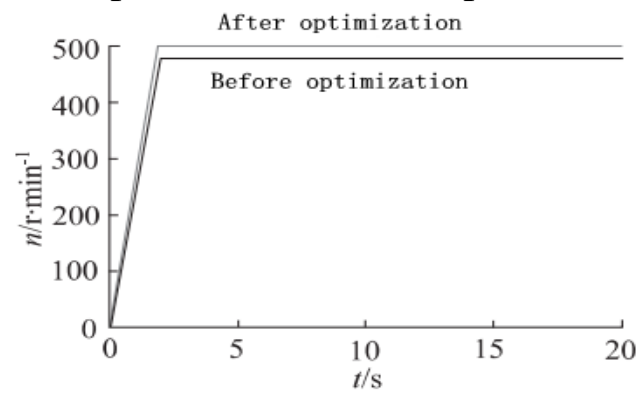

Fig. 6 The curve before optimization and the optimization of the secondary motor

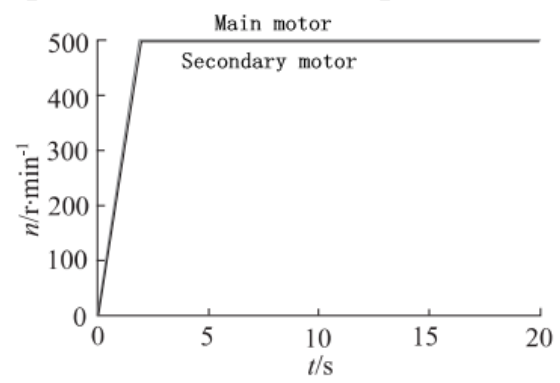

Fig.7 The synchronous speed curve of the optimized main motor and secondary motor

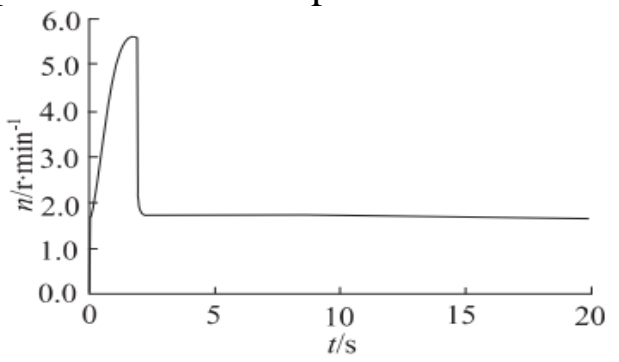

Fig. 8 The synchronous error curve of the optimized main motor and secondary motor

\section{Conclusion}

The study is mainly from a control theory perspective, without changing the physical system under the premise, and affect system performance of PID parameters was optimization design by the using of batch and genetic algorithm function of simulation analysis software AMESim. Search the optimal solution of the corresponding parameters in the global scope, and achieve the purpose of the whole system control part optimization. Research results show that, through optimization of PID parameters, each performance index of the system synchronization is improved, and meet the synchronization system design requirements and provide technical support and method development for parameter optimization. 


\section{References}

[1] Chang L J, Lin S Z, Zheng H W, et al. Hydraulic System Research of the Pumping Unit Based on Electro-Hydraulic Proportional Control Technology[J]. Applied Mechanics \& Materials, 2013, 373-375(373-375):1340-1344.

[2] Lixia L I, Mao X, Bian D. Design the Electrohydraulic Proportional Flow Control System Based on PLC [J]. Machine Tool \& Hydraulics, 2013.

[3] Xie N, Chen P W, Guo J J, et al. Analysis and Optimization of Electro-Hydraulic Proportional Speed Synchronous System Based on AMESim [J]. Applied Mechanics \& Materials, 2013, 391:228-231.

[4] Luo Y, Zhang C, Wang Q. Research on Self-Tuning Fuzzy PID Control for Electro-Hydraulic Proportion Positional Control System of Robotic Excavator[J]. Ordnance Industry Automation, 2014.

[5] Chen G, Shi G, Huang R. Research on Double-Axis Electro-Hydraulic Proportional Loading Control System With Intelligent Dual-PID for Membrane Materials[C]// ASME/BATH 2014 Symposium on Fluid Power and Motion Control. American Society of Mechanical Engineers, 2014: V001T01A018-V001T01A018.

[6] Lu Z, Sun M, Zhou J, et al. Research on control algorithm of reheating furnace walking beam based on electro-hydraulic proportional system [J]. Electronic Measurement Technology, 2014.

[7] Yuan X D, Xie Y C, Hua J H. Research on PID Control of Electro-Hydraulic Position Servo Control System Based on SDO Optimization[J]. Advanced Materials Research, 2014, 926-930:1396-1399.

[8] Zhang G, Huang J, Xia Y. Research on Fuzzy PID Control for Electrohydraulic Proportional Servo System Based on PLC[J]. Machine Tool \& Hydraulics, 2014.

[9] Liang C, Wang X, Ji J, et al. Research of PID Algorithm for Valve Controlled Hydraulic Motor Variable Rate Fertilizer Control System[M]// Computer and Computing Technologies in Agriculture VII. Springer Berlin Heidelberg, 2014:315-326.

[10]Hao Y, Huang J, Li W, et al. Research on the performance of electro-hydraulic proportional flow valve controlled by pilot pump[C]// Fluid Power and Mechatronics (FPM), 2015 International Conference on. IEEE, 2015.

[11]Moonumca P, Depaiwa N, Yamamoto Y. Tuning PID Controller Using Genetic Algorithms for Electro-Hydraulic System with Tracking Force Control [J]. Advanced Materials Research, 2014, 931-932:1318-1322. 